\title{
The Impact of Perceived Destination Restorative Qualities on Chinese Tourists' Behavioral Intention After Visiting Thailand
}

\author{
Jin LU iD a Fuangfa AMPONSTIRA iD b \\ a Ph.D. Candidate, Management, School of Management, Shinawatra University, jhlujin@qq.com \\ b Management, School of Management, Shinawatra University, fuangfa.a@siu.ac.th
}

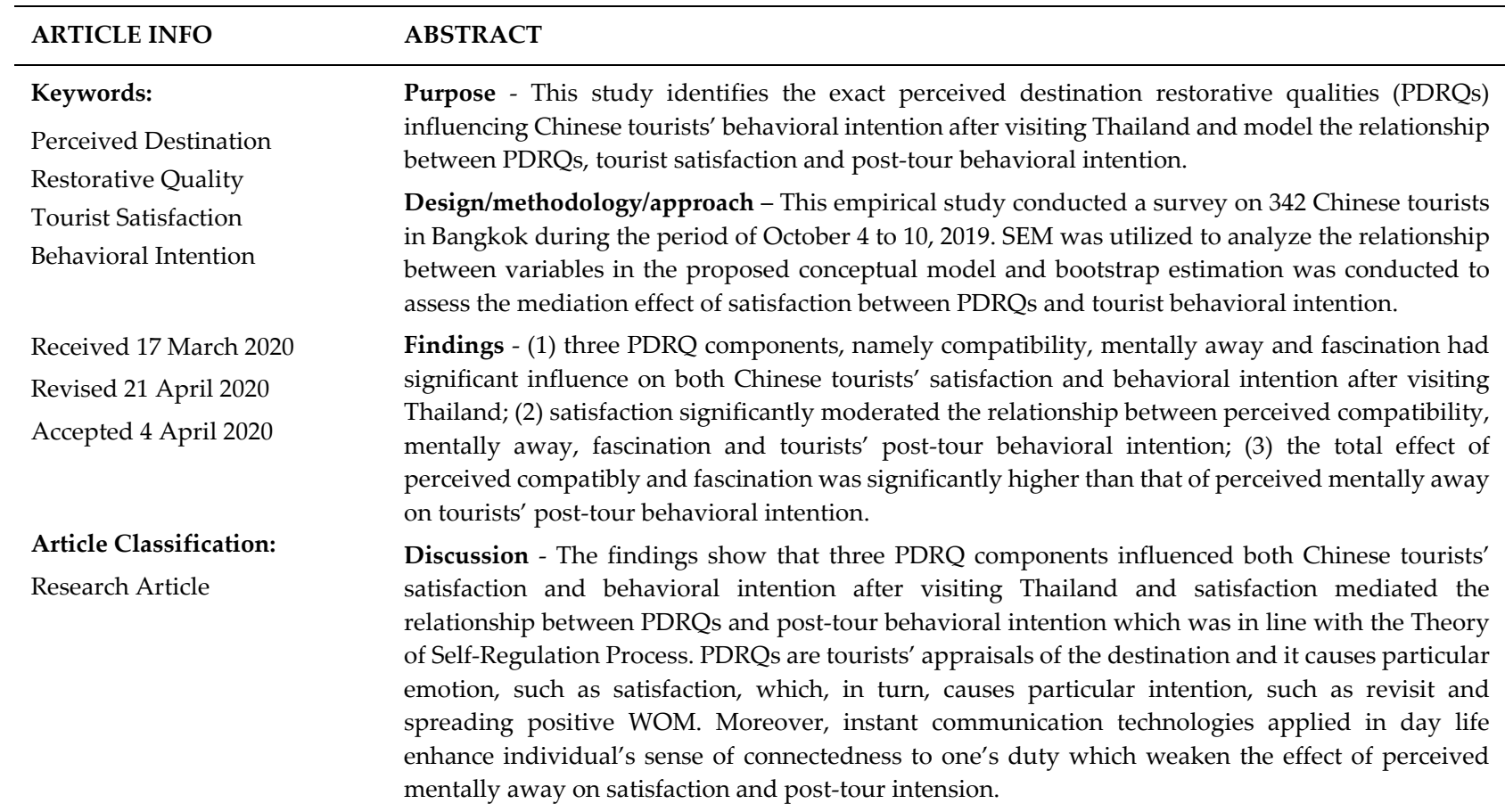

\section{Introduction}

Tourism is a major contributor to the economy of Thailand. Estimates of direct contribution of travel and tourism to GDP of Thailand was 49 billion U.S. Dollars, the equivalent of $9.62 \%$ of total GDP, in 2018 . When including indirect travel and tourism receipts, the 2018 total was 109.5 billion dollars, which took up $21.6 \%$ of the country's GDP (KNOEMA, 2019). As all known, China market is the most important for Thai tourism, which contributed 10.6 million visitors out of the overall 38.18 million international arrivals in 2018, the equivalent of a quarter of the total (Ministry of Tourism and Sport of Thailand, 2019). However, some critical problems emerged in this biggest oversea tourist market of Thailand in recent years. The growth rate of Chinese tourist arrivals has shrunk for two years since 2018, in spite of stimulating entry policy of waiving 2000-both of visa-on-arrival fee of Chinese tourists starting from the end of 2018. (Kasikorn Research Center, 2019).

Thai tourism statistics show there is a huge difference in revisiting rate between tourists from China and western countries. In Thailand, $60 \%$ of western tourists are return visitors (McDowall, 2010) while this rate is only $40 \%$ regarding to Chinese tourists (Ministry of Tourism and Sport of Thailand, 2017). As Thailand hosts over 10 million Chinese tourists a year, every single increasement of $10 \%$ revisiting rate means 1 million extra Chinese arrivals to Thailand. Obviously, investigating Chinese tourists' experience in Thailand and

\section{Önerilen Atıf/ Suggested Citation}

Lu, J., Amponstira, F. (2020). The Impact of Perceived Destination Restorative Qualities on Chinese Tourists' Behavioral Intention After Visiting Thailand, Journal of Business Research-Turk, 12 (2), 1006-1013. 
influencing factors to their post-tour behavioral intention would be an effective strategy to solve Thailand's problem in China market.

With rapid development of modernization and urbanization in China, most people are suffering from daily work and life stress. The negative affection of overtime work introduced fatigue on people has already been a national public concern. Consequently, leisure and relaxation has already taken the place of seeking novelty and become the top tourism motivation in China. Based on this fact, it's reasonable to assume Chinese tourists' perception of environmental restorativeness has significant influence on their behavioral intention, such as revisit and spreading positive word of mouth, after visiting Thailand. However, such noteworthy topic has been totally ignored by tourism scholars.

To fill this research gap, present research attempts to identify those exact perceived Thai destination restorative qualities (QDRQs) influencing Chinese tourists' behavioral intention after visiting Thailand and investigate the relationship between PDRQs, tourists' satisfaction and their behavioral intention after visiting Thailand.

\section{Literature Review}

\subsection{Attention Restoration Theory (ART)}

The Attention Restoration Theory (ART; Kaplan,1995) is a foundational theory on restorative environments. The core of ART is the concept of attention, which is composed of directed attention and involuntary attention. Directed attention is used when human beings are doing something don't capture attention automatically. Then effort is needed to direct attention on them and inhibit all distractions at the same time. This process leads to directed attention fatigue, which is harmful to people's work performance and well-beings (Kaplan et al., 1993). According to ART, directed attention will be replenished when people stay in places where the Kaplans define as restorative environments, such as visiting to a zoo (Pals et al.,2009), staying in a tourism resort (Guo et al.,2014), participating in outdoor recreations in a national park (Kim et al., 2014), taking a walk in a forest (White et al., 2013) and so on. A restorative environment, natural or human built, is usually eyecatching and featured in abundant involuntary attention stimuli. Interacting with such environment requires minimum directed attention because involuntary attention is attracted automatically by the features of the environment itself. Therefore, the restoration of directed attention takes place (Ouellette et al.,2005).

In ART, Kaplan identified four qualities of restorative environments generating recovery from directed attention fatigue: fascination, being away, extent and compatibility (Kaplan \& Kaplan, 1989). Fascination, defined as those natural eye-catching qualities of environment, is critical to the recovery of directed attention fatigue. Being away includes the concept of both physical and mental distance from one's daily work or living environment, which requires the use of directed attraction. Extent, including two important properties of connectedness and scope, defines one's perception of the degree of spatial scale for exploration and the recognition of the coherence of internal and external landscape elements. Compatibility refers to the correspondence between individual's inclinations, requirements made by the environment conditions and information available in the environment for support of one's goal.

\subsection{Measures of Perceived Environmental Restorative Qualities}

Guided by ART, numbers of measures have been developed for measuring the perception of environment restorative qualities. Terry Hartig et al. (1997) proposed a 4-factor model named Perceived Restorativeness Scale (PRS). The PRS is the first tool developed for measuring perceived environment restorative qualities and its four indicators, including fascination, being away, extent and compatibility, are consistent with ART. Following up Hartig's PRS, Laumann et al. (2001) proposed another tool with five factors including twentytwo items, Restorative Components Scale (RCS). In RCS, the factor of being away of ART splits into two parts, novelty (physically being away) and escape (mentally being away). Inspired by PRS and RCS, Pals et al. (2009) designed new measure, Perceived Restorative Characteristic Questionnaire (PRCQ). In PRCQ, the definition of extent refers to the degree of coherence between elements in the environment, and how well all elements go together.

The research in restorative qualities in travel and tourism settings has been relatively underdeveloped, till Lehto (2013) developed Perceived Destination Restorative Qualities (PDRQ) scale. This measure contains six 
factors with thirty items: compatibility, extent, mentally away, physically away, discord and fascination. The first factor compatibility actually covers two factors presented in previous studies. Six out of nine items of this factor measure correspondence between visitor's expectation and destination itself, while the rest three items, similar with the idea of coherence in previous studies, measure the connectedness between things inside the destination. The second factor is extent with five items measuring the scope of the destination. The third one is mentally away and the fourth one is physically away with four and three items respectively, expressing the same idea as novel and escape in Laumann's scale of RCS. The fifth factor, labeled discord, is original in PDRQ with four items, measuring distractions a tourist perceived in a destination. The last factor, fascination, is strictly consistent with the idea of Kaplan's ART.

\subsection{Perceived Destination Restorativeness \& Tourist Satisfaction/Behavior}

With the development of above-mentioned scales, the relationship between perception of environment restorative qualities, tourist satisfaction and behavior in different settings were assessed. Laumann et al. (2001) advocate the perception of compatibility and fascination could work as predictors of people preference of environment. Pals' (2009) surveys on 325 zoo visitors suggest perception of environmental factors of fascination and escape are significant predictors of visitor preference of zoo attractions. Kim (2014) conducted a survey in a national park in Korea and verified his model of relationship between people's perceived environmental restorativeness, satisfaction and loyalty. Chinese scholar Chen et al. (2017) verified the validity of PDRQ scale in the context of Chinese culture in his research with Chinese vacationers in a forest resort. Chen points out two subscales of PDRQ, fascination and compatibility, are predictable to satisfaction and posttour behavioral intentions. More important, he claims the subscales of discord is simply not a factor reflecting environment restoration perception and Chinese people influenced by the cultural values of pursuing "unity of Yin and Yang" tend to "accept contradictions as part of the natural order". Following Chen's suggestion, the dimension of discord was removed from present study.

\section{Research Hypotheses}

Based on above-mentioned theory and related studies, two hypotheses were proposed as follow:

Hypothesis 1: PDRQs have significant influence on Chinese tourists' behavioral intention after visiting Thailand.

Hypothesis 2: Tourists' satisfaction mediates the relationship between PDRQs and their behavioral intention after visiting Thailand.

\section{Methodology}

Quantitative research was utilized in present study. The relationship of five dimensions (excluding discord) of PDRQ, tourist satisfaction and post-tour behavioral intention were tested by SEM applying AMOS 24.0 with data collected from questionnaire research.

\subsection{Instrument}

The questionnaire consisted of 3 parts, worded in Mandarin Chinese. Part one utilized PDRQ scale. 26 statements (with exception of 4 items of discord) were followed with a 7-point Likert rating scale with "1" labelled "not agree at all" at one end and "7" labelled "extremely agree" at the other. Part two contained 8 items derived from existent researches (Kim et al., 2014; Chen and Xi, 2018) assessing respondents' satisfaction and post-tour behavioral intention with 7-Likert scale as well. The last part collected respondents' demographic information and tour characteristics. Before distributing the questionnaire, 6 Chinese PHD students of management were invited to a pretest. Some adjustments regarding to understandability and clarity were made according to their feedback.

\subsection{Sample $\mathcal{E}$ data collection}

The scope of population of present study was Chinese people with recent experience of visiting Thailand. Samples were approached at the international departure hall of Bangkok Suvarnabhumi Airport during the period of October 4 to 10, 2019. In this period, 400 Chinese tourists, who just finished their vacation and were about to depart Thailand, were asked to fill in the questionnaire in relation to their experience in Thailand. This process resulted in 342 completed questionnaires and the response rate was $85.5 \%$. 
The profiles of respondents and trip characteristics are displayed in Table 1 below. More group tourists (54.4\%) were surveyed than independent tourists $(45.6 \%) .65 .2 \%$ of them were on their first trip to Thailand, while the other $34.8 \%$ were return visitors. The length of the vacation most respondents took was 5-9 days (82.4\%).

Table 1. Respondent Demographics and Trip Characteristics

\begin{tabular}{|c|c|c|c|c|c|}
\hline Variable & Category & Distribution & Variable & Category & Distribution \\
\hline \multirow{2}{*}{ Gender } & Male & $53.2 \%$ & \multirow{2}{*}{ Group or FIT } & Group & $54.4 \%$ \\
\hline & Female & $46.8 \%$ & & FIT & $45.6 \%$ \\
\hline \multirow{3}{*}{ Age } & $\leq 30$ & $36.5 \%$ & \multirow{3}{*}{$\begin{array}{l}\text { Length of } \\
\text { visiting (day) }\end{array}$} & $\leq 4$ & $4.7 \%$ \\
\hline & $31-60$ & $48 \%$ & & $5-9$ & $82.4 \%$ \\
\hline & $\geq 61$ & $15.5 \%$ & & $\geq 10$ & $12.9 \%$ \\
\hline \multirow{3}{*}{ Education } & $\begin{array}{l}\text { High school and } \\
\text { below }\end{array}$ & $35.4 \%$ & \multirow{3}{*}{$\begin{array}{l}\text { Times of visiting } \\
\text { Thailand }\end{array}$} & 1 & $65.2 \%$ \\
\hline & Undergraduate & $45.9 \%$ & & $2-4$ & $31.3 \%$ \\
\hline & Graduate and above & $18.7 \%$ & & $\geq 5$ & $3.5 \%$ \\
\hline
\end{tabular}

\section{Results and Discussion}

\subsection{Confirmatory Factor Analysis}

Anderson and Gerbing (1982) assert good measurement of the latent variables is prerequisite to the analysis of the causal relations among the latent variables. Following their suggestion, the measurement models were evaluated one by one with AMOS 24.0 before assessing the structural model. As a result, all constructs passed model fit test, except the construct of compatibility $\left(X^{2}=574.920, X^{2} / D F=21.293, G F I=0.689\right.$, AGFI $=0.482$, RMESA $=0.244$ ) (Hair et al., 2006). Guided by modification indices, item $C P 2, C P 6, C P 9$ were removed from the construct of compatibility. Consequently, the revised model $\left(\mathrm{X}^{2}=24.332, \mathrm{X}^{2} / \mathrm{DF}=2.704, \mathrm{GFI}=0.978, \mathrm{AGFI}=0.949\right.$, RMESA=0.071) suggested satisfying model fit.

Table 2. CFA Results

\begin{tabular}{|c|c|c|c|c|}
\hline Factors & SFL & SMC & C.R. & AVE \\
\hline \multicolumn{5}{|l|}{ Compatibility } \\
\hline CP1. The destination I visited was consistent with who I am. & .901 & .812 & \multirow{7}{*}{.951} & \multirow{6}{*}{.763} \\
\hline CP3. Thailand suits my personality. & .921 & .848 & & \\
\hline CP4. I have a sense of oneness with Thailand. & .914 & .835 & & \\
\hline CP5. Everything I saw in Thailand belongs there. & .770 & .593 & & \\
\hline CP7. Thailand was my kind of place. & .921 & .848 & & \\
\hline CP8. The things I like to do can be done in Thailand. & .801 & .642 & & \\
\hline \multicolumn{4}{|l|}{ Extent } & \\
\hline EX1. There was a variety of things to do in Thailand. & .906 & .821 & \multirow{6}{*}{.955} & \multirow{5}{*}{.810} \\
\hline EX2. I could do many things in Thailand. & .912 & .832 & & \\
\hline EX3. I did different things in different areas in Thailand. & .907 & .823 & & \\
\hline EX4. Thailand was large enough to allow exploration. & .889 & .790 & & \\
\hline EX5. Thailand allowed me to explore extensively. & .886 & .785 & & \\
\hline \multicolumn{4}{|l|}{ Mentally away } & \\
\hline MA1. In Thailand, I could forget about my obligations. & .871 & .759 & \multirow{5}{*}{.907} & \multirow{4}{*}{.710} \\
\hline MA2. In Thailand, I felt that I was away from everything. & .893 & .797 & & \\
\hline MA3. When I was in Thailand, I felt free from my daily routine. & .782 & .612 & & \\
\hline MA4. I felt free from all the things that I normally have to do. & .819 & .671 & & \\
\hline \multicolumn{4}{|l|}{ Physically away } & \\
\hline $\begin{array}{l}\text { PA1. Being in Thailand, I felt as if I was in surroundings different to } \\
\text { my normal living environment. }\end{array}$ & .747 & .558 & \multirow{3}{*}{.834} & \multirow{3}{*}{.627} \\
\hline PA2. In Thailand, I did different things from when I was home. & .763 & .582 & & \\
\hline $\begin{array}{l}\text { PA3. Thailand was very different from my daily environment. } \\
\text { Fascination }\end{array}$ & .860 & .740 & & \\
\hline FA1. For me, visiting Thailand was a captivating experience. & .911 & .830 & .947 & .783 \\
\hline
\end{tabular}




\begin{tabular}{lllll}
\hline Factors & SFL & SMC & C.R. & AVE \\
\hline FA2. My attention is drawn to interesting things about Thailand. & .906 & .821 & & \\
FA3. There was much to explore and discover in Thailand. & .903 & .815 & \\
FA4. I found Thailand fascinating. & .847 & .717 & \\
FA5. Being in Thailand makes me wonder about many things & .855 & .731 & \\
Satisfaction & & & \\
SA1. Visiting Thailand satisfied my expectation. & .888 & .789 & \\
SA2. It was a great decision to visit Thailand. & .906 & .821 & \multirow{2}{*}{.757} \\
SA3. I feel very good with visiting Thailand. & .833 & .694 & \\
SA4. Overall, I was satisfied with visiting Thailand & .850 & .723 & & \\
Behavioral intention & & & & \\
BI1. I'd like to visit Thailand next time. & .813 & .661 & & \\
BI2. I'll prioritize Thailand over other destinations. & .855 & .731 & \multirow{2}{*}{.913} & .725 \\
BI3. I'll recommend Thailand to my families and friends. & .888 & .789 & & \\
BI4. I'll spread positive WOM about Thailand. & .848 & .719 & & \\
\hline
\end{tabular}

Note: AVE: average variance extracted; CR: composite reliability; SFL: standardized factor loading; SMC: squared multiple correlation

Subsequently, the overall model fit was examined. The $\mathrm{X}^{2} / \mathrm{DF}$ value was $1.491\left(1<\mathrm{X}^{2} / \mathrm{DF}<3\right)$ and the Root Mean Square Residua $(\mathrm{RMR})$ value was $0.076(<0.08)$, which indicated an overall good fit; the Comparative Fit Index (CFI) was 0.979, Incremental Fit Index (IFI) was 0.979, and Tacker-Lewis Index (TLI) was 0.976, all larger than the critical value of 0.90 ; the RMSEA value was 0.038 less than the thresh-old value of 0.08 . Altogether, these values of the fit indices suggested that the model fit the data adequately.

Then the construct validity and reliability were tested (see Table 2). The standard factor loadings for all 31 items were between 0.747 and 0.921 ; the SMC values of all seven constructs were between 0.558 and 0.848 ; and the composite reliability values of the constructs were between 0.834 and 0.955 . According to Hair et al. (2006), the above results suggested satisfactory reliability of the questionnaire.

As shown in Table 2, the standard factor loadings for all 31 items were between 0.747 and $0.921(>0.5)$ and the values of average variance extracted were between 0.627 and $0.810(>0.5)$ ), indicating sufficient convergent validity. The discriminant validity of the scale was also examined following Fornell and Larcker (1981). As show in Table 3, the square root of AVEs of all the seven constructs exceeded the corresponding correlations between the constructs. Therefore, it could be concluded that the assessment of the measurement model indicated satisfactory reliability and construct validity of the questionnaire.

Table 3. Construct Inter-Correlations

\begin{tabular}{lccccccc}
\hline & SA & BI & PA & MA & FA & EX & CP \\
\hline Satisfaction & $.870^{\mathrm{a}}$ & & & & & & \\
Behavioral Intention & .679 & $.851^{\mathrm{a}}$ & & & & & \\
Physically away & .180 & .171 & $.792^{\mathrm{a}}$ & & & & \\
Mentally away & .274 & .296 & .095 & $.843^{\mathrm{a}}$ & & & \\
Fascination & .699 & .669 & .212 & .203 & $.885^{\mathrm{a}}$ & & \\
Extent & .404 & .441 & .113 & .133 & .489 & $.900^{\mathrm{a}}$ & \\
Compatibility & .575 & .639 & .202 & .235 & .609 & .406 & $.873^{\mathrm{a}}$ \\
\hline
\end{tabular}

Note: a square root of average variance extracted

\subsection{Model and hypothesis test}

Maximum likelihood estimation was conducted by AMOS 24.0 to evaluate the model validity. Figure 1 indicates the standard path coefficients of the proposed model. According to Figure 1 the perceived destination characteristics of compatibility (at C.I. of $99.9 \%$ ), mentally away (at C.I. of $95 \%$ ) and fascination (at C.I. of $99.9 \%$ ) appeared to have significant influence on both tourists' satisfaction and post-trip behavioral intention, while PDRQ components of extent, discord and physically away didn't have significant effect on 
both tourists' satisfaction and their post-tour behavioral intention. In addition, tourists' satisfaction significantly affected post-tour behavioral intention.

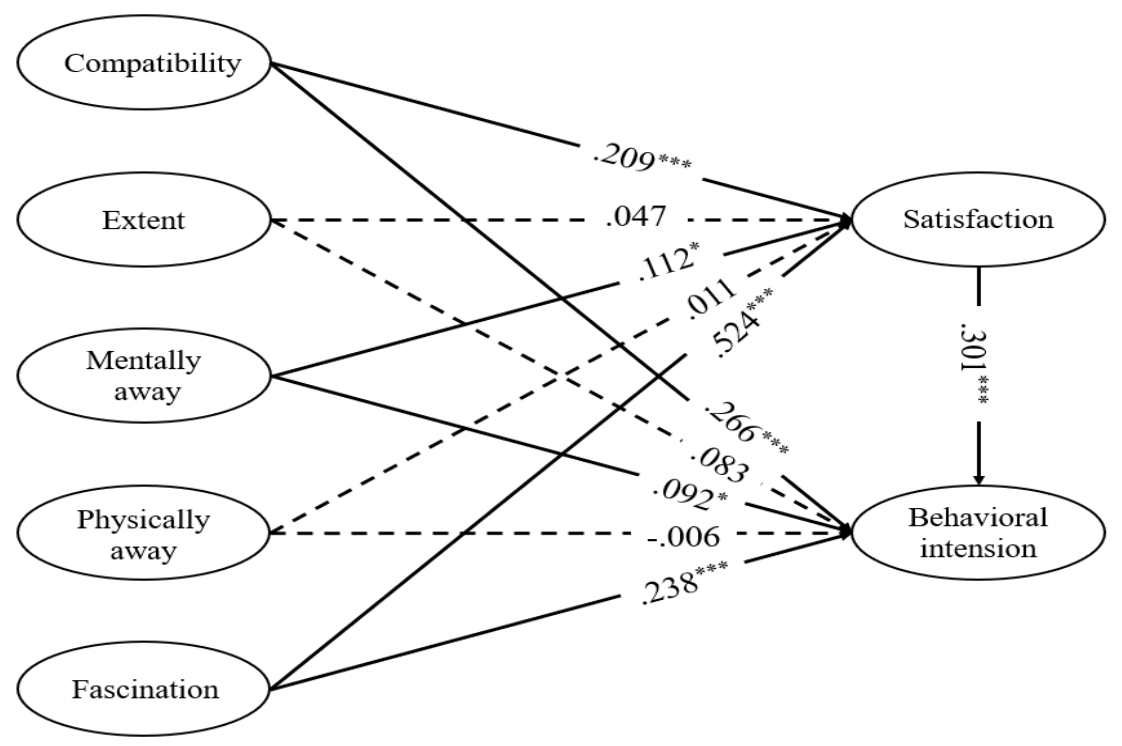

Note: * significant at $\mathrm{p}<.05 ;{ }^{* * *}$ significant at $\mathrm{p}<.001$

Figure 1. Structural Results of The Proposed Model

Subsequently, we assessed the direct effect, indirect effect, total effect and total effect difference of PDRQs on behavioral intention following the process Sobel (1982) suggested. We applied the method of bootstrap at 5000 times with confidence interval at $95 \%$ by Amos 24.0. The result of the assessment is reported in table 4 .

Table 4. Effect of PDRQs on Behavioral Intention

\begin{tabular}{|c|c|c|c|c|c|c|c|c|}
\hline \multirow{3}{*}{ Variances } & \multirow{3}{*}{ Point Estimation } & \multirow{2}{*}{\multicolumn{2}{|c|}{$\begin{array}{l}\text { Product of } \\
\text { Coefficients }\end{array}$}} & \multicolumn{5}{|c|}{ Bootstrapping } \\
\hline & & & & \multicolumn{2}{|c|}{$\begin{array}{l}\text { Bias-Corrected } \\
(95 \% \text { C.I. })\end{array}$} & \multicolumn{2}{|c|}{$\begin{array}{l}\text { Percentile } \\
\text { (95\% C.I.) }\end{array}$} & \multirow[t]{2}{*}{$\mathrm{P}$} \\
\hline & & SE & $\mathrm{Z}$ & Lower & Upper & Lower & Upper & \\
\hline \multicolumn{9}{|c|}{ INDIRECT EFFECT } \\
\hline $\mathrm{CP}->\mathrm{SA}->\mathrm{BI}$ & .061 & .031 & .061 & .017 & .164 & .012 & .132 & $* * *$ \\
\hline $\mathrm{MA}->\mathrm{SA}->\mathrm{BI}$ & .037 & .028 & .037 & .001 & .109 & .002 & .115 & $* * *$ \\
\hline FA->SA->BI & .153 & .062 & .153 & .071 & .320 & .063 & .308 & $* * *$ \\
\hline \multicolumn{9}{|c|}{ DIRECT EFFECT } \\
\hline $\mathrm{CP}->\mathrm{BI}$ & .258 & .071 & .258 & .137 & .415 & .132 & .405 & $* * *$ \\
\hline $\mathrm{MA}->\mathrm{BI}$ & .102 & .044 & .102 & .016 & .198 & .005 & .187 & $* * *$ \\
\hline FA->BI & .231 & .077 & .231 & .084 & .389 & .078 & .378 & $* * *$ \\
\hline \multicolumn{9}{|c|}{ TOTAL EFFECT } \\
\hline CP->BI TE & .318 & .073 & .318 & .194 & .483 & .191 & .481 & $* * *$ \\
\hline MA->BI TE & .139 & .048 & .139 & .045 & .246 & .039 & .238 & $* * *$ \\
\hline FA->BI TE & .384 & .065 & .384 & .262 & .521 & .264 & .522 & $* * *$ \\
\hline \multicolumn{9}{|c|}{ TOTAL EFFECT DIFFERENCE } \\
\hline CP-MA TE diff & .179 & .097 & .179 & .015 & .387 & .016 & .388 & $* * *$ \\
\hline CP-FA TE diff & -.066 & .116 & -.066 & -.274 & .187 & -.286 & .164 & .574 \\
\hline MA-FA TE diff & -.246 & .084 & -.246 & -.400 & -.076 & -.416 & -.094 & $* * *$ \\
\hline
\end{tabular}

Note: $\mathrm{CP}=$ compatibility; $\mathrm{MA}=$ mentally away; $\mathrm{FA}=$ fascination; $\mathrm{SA}=$ satisfaction; $\mathrm{BI}=$ behavioral intention

As indicated in table 4 above, the mediation effect of satisfaction on the relationship between compatibility, mentally away and fascination were significant. Moreover, there was no significant difference between total effect of compatibility and fascination and they were both significantly higher than that of mentally away. 


\subsection{Discussion}

First of all, PDRQ components of compatibility and fascination were found to be significant predictors to Chinese tourists' satisfaction and behavioral intention after visiting Thailand, which echo similar existent studies (Laumann et al., 2001; Chen and $\mathrm{Xi}, 2018$ ) based on different types of destinations. The perceived environmental characteristic of mentally away, which is insignificant in Chen and Xi's (2018) study, is also found to be significant on predicting Chinese tourists' satisfaction and behavioral intention, although it's significantly weaker than the former two components. The reason should be: with modern tools of transportation and communication, it's difficult for Chinese people to be free from daily obligation and duty even when they are on vacation in China. But when they are in a foreign country, the relatively far geographic distance provides the possibility of the perception of escaping from their daily obligation and duty, which meets their travel motivation.

Second, satisfaction mediated the relationship between some of PDRQs, namely compatibility, fascination and mentally away, and Chinese tourists' behavioral intention after visiting Thailand. This finding can be explained by Bagozzi's (1992) Theory of Self-regulation Process. In this case PDRQs are tourists' appraisals of the destination and it would cause particular emotion, such as satisfaction. As outcome of such emotion, particular intention, such as revisit or spreading positive WOM occurs.

\section{Conclusion and implication}

\subsection{Conclusion}

Present study explores the way how perceived Thailand destination restorative qualities influence Chinese tourists' satisfaction and post-tour behavioral intention. SEM analysis indicates: three components out of five tested PDRQs, compatibility, mentally away and fascination, had both direct and indirect (via mediation of satisfaction) on Chinese tourists' behavioral intention after visiting Thailand. This research provides deep understanding of Chinese tourists' experience and behavioral intention from the view of environmental psychological analysis.

\subsection{Implications}

There is a renewed tourist emphasis on health and wellness in China tourism market. In order to turn more Chinese tourists into revisiting guests or positive WOM spreaders, Thai tourism marketing department, should establish a clear destination image of health and wellness through international marketing. A clear destination image helps people to form an appropriate travel expectation before arrival and those expectation should be satisfied by more attention paid to the production and management of the wellness domain of travel experience by Thai destination planners and managers to enhance Chinese tourists' perception of compatibility. Moreover, based on the connotation of compatibility, special attention should also be paid to design and management of tourism elements within destination and the protection of ecological environment to provide the sense of internal and external coherence of the destination.

Another two important components are fascination and mentally away. Mentally away is a sense of being distant from obligation, routines and duty in daily life. This implies "fascinations" in destination which Chinese tourists don't normally do at home, such as activities, shows, concerts and tasting Thai foods, are environmental stimuli of perception of both fascination and mentally away of Chinese. In order to enhance such perception, Thai destinations should invest more on tourism resources development, based on deep understanding of the requirements of Chinese tourists.

\section{3 limitation and suggestions}

Present study explores how Chinese tourists' perception of the restorative characteristics of Thailand on their post-tour behavioral intention. Besides the mediation effect of satisfaction, future research is invited to integrate and test more variables, such as tourism motivation, destination preference, overall mental recovery, etc. into the proposed model as mediation or moderation factors.

Additionally, as a whole, all Chinese tourists with experience of visiting Thailand were regarded as research population of present study. But tourists of different segment have distinguishing characteristics and interests, which influence the way how PDRQs work on their post-tour behavioral intention. Comparative studies between different categories of tourists in Thailand, for instance, between Chinese group tourists and FITs or between Chinese and Western tourists, can be an interesting area. 


\section{References}

Anderson, J.C., \& Gerbing, D.W. (1982). Some Methods for Prespecifying Measurement Models to Obtain Unidimensional Construct Measurement. Journal of Marketing Research, 19, 453-460.

Bagozzi, R.P.(1992). The self-regulation of attitudes, intentions and behavior. Social psychology quarterly, 55(2),178-204

Chen, G.H., \& Huang, S.S. \& Zhang, D.D. (2017). Understanding Chinese Vacationers' Perceived Destination Restorative Qualities: Cross-Cultural Validation of The Perceived Destination Restorative Qualities Scale. Journal of Travel \& Tourism Management, 34(8), 1115-1127

Chen, G.H., \& Xi, W. (2018). The Impact of Visitors' Perceived Destination Restorative Qualities on Satisfaction and Post-tour Behavioral Intentions: A Case Study of Nankunshan. Tourism Science, 32(4), 17-30.

Fornell, C., \& Larker, D.F. (1981). Evaluating structural equation models with unobservable variables and measurement error. Journal of Marketing Research, 18, 39-50.

Guo, Y., Zhang, J., Lu, S., Zhang, Y., Nian, S., \& Yan, B. (2014). The difference and structural model of tourist's perceived restorative environment. Tourism Tribune, 29(2), 93-102.

Hair, J.F., Black, W. C., Babin, B.J., Anderson, R.E., \& Tatham, R.L. (2006). Multivariate data analysis (6 ${ }^{\text {th }}$ ed.). Upper Saddle River, NJ: Pearson Education Inc.

Hartig, T., Korpela, K., Evans, G. W., \& Gärling, T. (1997). A measure of restorative quality in environments. Scandinavian Housing and Planning Research, 14(4), 175-194.

Kaplan, R., \& Kaplan, S. (1989). The experience of nature: A psychological perspective. New York, NY, US: Cambridge University Press.

Kaplan, S. (1995). The restorative benefits of nature: Toward an integrative framework. Journal of Environmental Psychology, 15, 169-182.

Kaplan, S., Bardewll, L.V., \& Slakter, D.B. (1993). The Museum as a Restorative Environment. Environment and Behavior, 25(6), 725-742.

Kasikorn Research Center (2019). Tourism reports. Retrieved from https://kasikornresearch.com /CH /analysis/kecon/business/Pages/index.aspx?c=362

Kim, J. O., Lee, J. E., \& Kim, N. J. (2014). An Influence of Outdoor Recreation Participants' Perceived Restorative Environment on Wellness Effect, Satisfaction and Loyalty. In SHS Web of Conferences (Vol. 12, p. 01082). EDP Sciences.

KNOEMA. (2019). Travel \& tourism direct contribution to GDP (Thailand). Retrieved from https://knoema.com/atlas/Thailand/topics/Tourism

Laumann, K., Gärling, T., \& Stormark, K. M. (2001). Rating scale measures of restorative components of environments. Journal of Environmental Psychology, 21, 31-44.

Lehto, X. Y. (2013). Assessing the perceived restorative qualities of vacation destinations. Journal of Travel Research, 52(3), 325-339.

McDowall, S. (2010). International Tourist Satisfaction and Destination Loyalty: Bangkok, Thailand. Asia Pacific Journal of Tourism Research, 15(1), 21-42.

Ministry of Tourism and Sport of Thailand. (2019). Tourism receipts from international tourist arrivals Q1-Q4 in Jan-Dec 2018. Retrieved from https://www.mots.go.th /mots_en/News-link.php?nid=3627

Ouellette, P., Kaplan, R., \& Kaplan, S. (2005). The monastery as a restorative environment. Journal of Environmental Psychology, 25(2), 175-188.

Pals, R., Steg, L., Siero, F.W., \& Zee, van der (2009). Development of the PRCQ: A measure of perceived restorative characteristics of zoo attractions. Journal of Environmental Psychology. 29(4), 441-449.

Sobel, M.E. (1982). Asymptotic Confidence Intervals for Indirect Effects in Structural Equation Models. Sociological Methodology, 13, 290-312.

White, M. P., Pahl, S., Ashbullby, K., Herbert, S., Snelling, S., \& Depledge, M. H. (2013). Feelings of restoration from recent nature visits. Journal of Environmental Psychology, 35, 40-51. 